\title{
Astronomy in Brazilian music and poetry
}

\author{
Ronaldo Rogério de Freitas Mourão \\ Museu de Astronomia e Ciências Afins, \\ Rua General Bruce, 586, São Cristóvão, Rio de Janeiro - 20921-030, Brazil \\ email: mourao@ronaldomourao.com
}

\begin{abstract}
The rôle of astronomy in the Brazilian cultural diversity -though little known worldhas been enormous. Thus, the different forms of popular music and erudite, find musical compositions and lyrics inspired by the stars, the eclipses in rare phenomena such as the transit of Venus in front of the sun in 1882, the appearance of Halley's Comet in 1910, in the Big Bang theory. Even in the carnival parades of the blocks at the beginning of the century astronomy was present. More recently, the parade of 1997, the samba school Unidos do Viradouro, under the direction of Joãozinho Trinta, offered a new picture of the first moments of the creation of the universe to join in the white and dark in the components of their school, the idea of matter and anti-matter that reigned in the early moments of the creation of the universe in an explosion of joy. Examples in classical music include Dawn of Carlos Gomes and Carta Celeste by Almeida Prado. Unlike The Planets by Gustav Holst -who between 1914 and 1916 composed a symphonical tribute to the solar system based on astrology- Almeida Prado composed a symphony that is not limited to the world of planets, penetrating the deep cosmos of galaxies. Using various resources of the technique for the piano on the clusters and static movements, violent conflicts between the records of super acute and serious instrument, harpejos cross, etc ...
\end{abstract}

Keywords. classical music, popular music, samba, poetry

\section{Introduction}

Astronomy has always attracted writers and musicians as a stimulus to their dreams. There are many works whose inspiration was born in contemplating the sky, in reading the works of astronomers or in the prediction of celestial phenomena in almanacs, and, these days, by way of all kinds of means of communication. In the musical domain, the English musician Gustav Holst (1874-1934) comes to mind, since, attracted by astrology, he composed, between 1914 and 1916, a symphony to the glory of the solar system, The Planets. In his case, however, he deliberately abandoned the scientific aspects in favour of a purely astrological vision, originating in a distant hermetic tradition, passed on by a recent theosophic faction founded by Elena Petrovna Blavatskaya in the 1880s.

Unlike Holst, the Brazilian musician Almeida Prado (1943-), inspired by astronomy, composed a symphony which is not limited to the world of the planets, but penetrates deep into the universe of the galaxies. In his composition for solo piano, the Cartas Celestes (1974) he made use of different resources of the pianist's technique, above all clusters, both static and in movement, violent opposition between the especially sharp and flat registers of the instrument, arpeggios used etc. Almeida Prado also composed Aurora (1973) for piano and orchestra, a title which reminds us of the song Aurora tramonto by the Brazilian composer Carlos Gomes (1836-1896), best known for his operas.

\section{Cartas celestes, Mapas do céu, by Almeida Prado}

The work Cartas celestes (Charts of the heavens) meant, to Almeida Prado, as he later was to confess: 


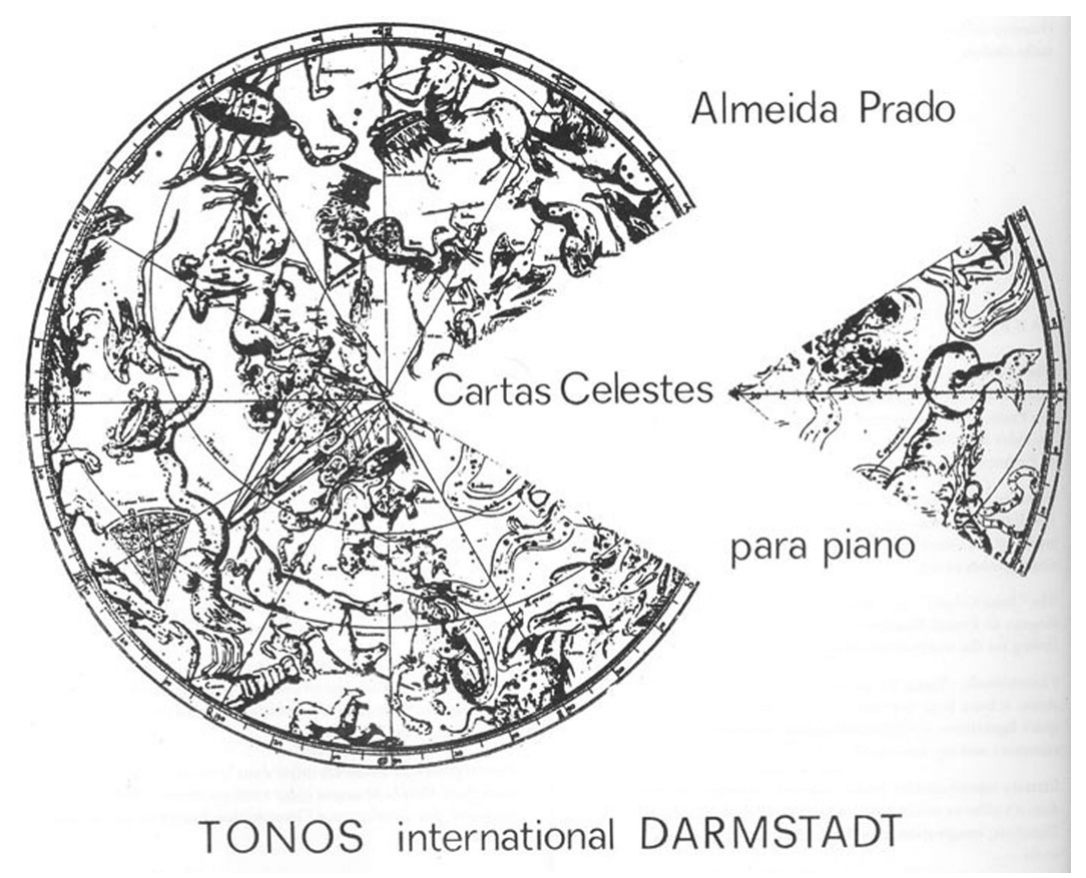

Figure 1. Almeida Prato's Cartas celestes.

[...] "a great adventure, something I threw myself at without knowing where it would end, like a rocket blasts off from earth with no coming back. It all started with a commission from José Luis Paes Nunes, in July 1974, for a spectacle at the Ibirapuera Planetarium in São Paulo.

I composed the work as a piano solo, since this was easier to execute in a short space of time. In its original form, it lasted more or less one hour; afterwards, I redid it and it grew shorter. Immediately, the idea came to me to find my inspiration in the Cartas Celestes, which explains the title of my composition.

I used the book Atlas Celestes by Ronaldo Rogério de Freitas Mourão as a dependable guide to this fantastic voyage across the Cosmos. This superb astronomer-poet showed Brazil's sky in the charts of the heavens, every two months. In Carta Celeste I, the months of August and September -the beginning of Winter and of Spring."

To meet the challenge of composing within a short space of time, Almeida Prado resorted to the piano, an instrument with much resonance which gave the sonorous content immense continuity of sounds and, thus the pedal came to the fore, gaining outstanding importance.

To represent the full splendour of the universe, Almeida Prado used a complex of new sound effects -large agglomerations of very rapid clusters, in a sequence the shape of a spiral, flashing arpeggios, trilling trebles, super-rapid tremolos with the pedal, upper harmonics as a basis for the transtonalism, chromatic glissandos (white and black piano keys, simultaneously).

Since stars are designated using the Greek alphabet, according to their luminous intensity in the constellations, Almeida Prado created twenty-four different chords to stand in for them in the constellations. These chords unified the whole work begun in 1974 .

Almeida Prado explains:

"Seven years went by; in this period I changed a lot. My music was, little by little, becoming enriched by new influences, becoming more human, nearer 
$\alpha$

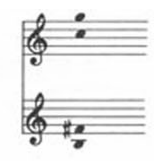

$\varepsilon$

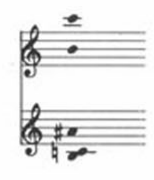

l

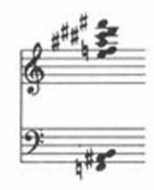

$x$

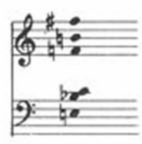

$\xi$

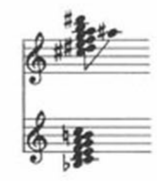

$\sigma$

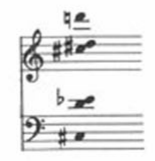

$\varphi$
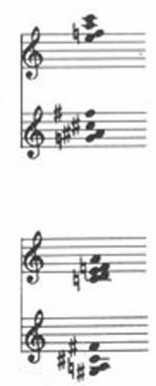

$\beta$
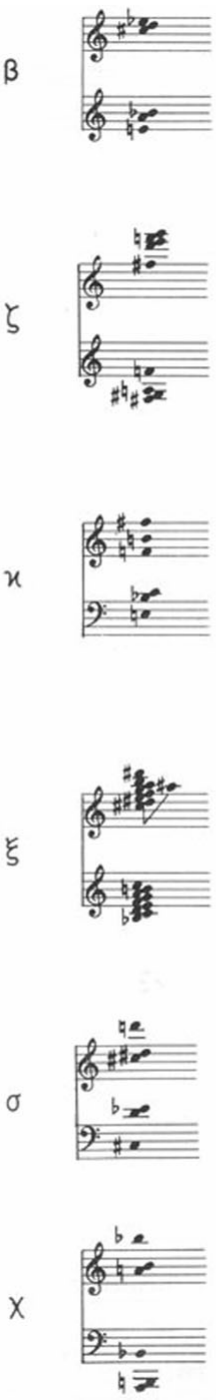

$\gamma$

$\eta$

$\lambda$

o
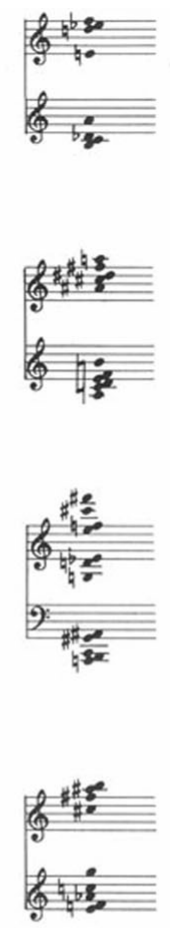

$\tau$

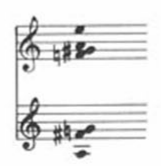

$\delta$

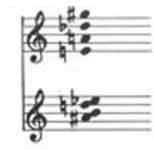

$v$

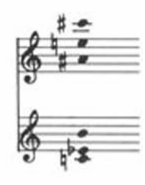

$\mu$

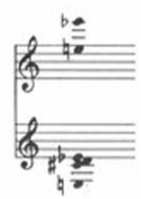

$\pi$

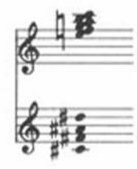

ข

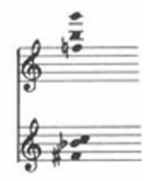

$\psi$

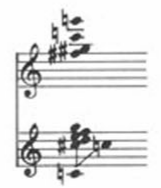

$\bar{\omega}$

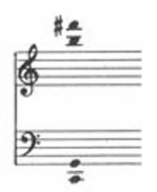

Figure 2. 24 chords standing for constellations in Almeida Prato's Cartas celestes.

things related to nature; a fertile period, in which $I$ was strongly influenced by ecology."

However, Almeida Prado wrote:

"a picturesque, anecdotal fact, made me go back to composing this cosmic cycle. One night, searching for a sheet of Bach's music, I found, by chance, Mourão's Atlas Celeste. I opened it exactly, coincidentally, at the page where the months of October and November were: was it a sign for me to continue? My wife, Helenice, with loving intuition, spurred me on to the task. However, I had changed. My composing, more fluent now, was revealing another aspect of myself: how could I continue the work? $A$ voice inside me said: do it! The solution came to me rapidly. The twenty-four Greek alphabet chords would be the solution. A transposition into intervals different from those presented in the first work; I would do it in different versions for the remaining volumes. Eureka! The solution had materialized. By taking this path, I succeeded in capturing the continuity of the sonorous discourse." 

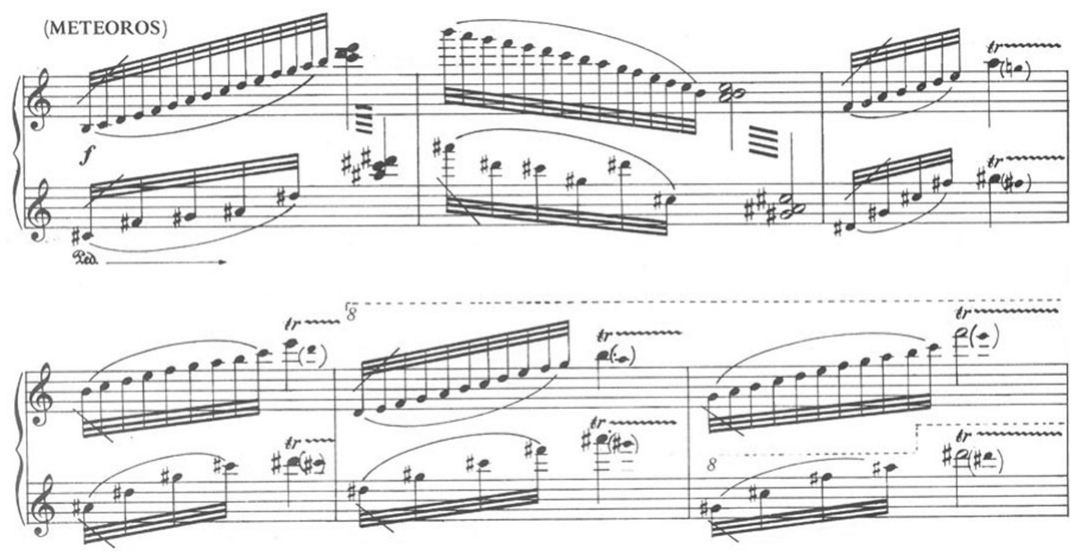

Figure 3. Extract from Almeida Prato's Cartas celestes.

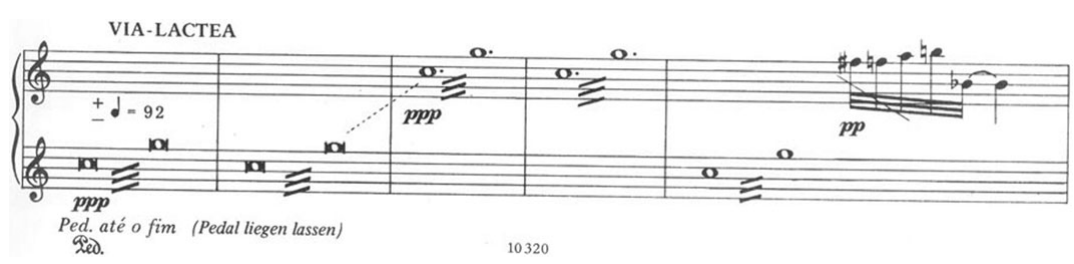

Figure 4. Part of the Milky Way from Almeida Prato's Cartas celestes.

For the second volume of the Cartas celestes, Almeida Prado developed arpeggios with harmonics, in a sort of coloured spiral, going from one nucleus to another, uninterruptedly. In effect, in the first volume, the appearance of the planet Venus arises timidly and rapidly; in the second, Mercury and Uranus appear more emphatically. In the same perspective as the Cartas celestes, the piece Ore Jacy-Tatá is a return to the celestial charts. Ore-Jacy-Tatá is a name of Tupi-Guarani origin, meaning our stars. This symphonic piece in three movements, Almeida Prado composed as a commission from the Ministry of Culture commemorating the 500th anniversary of the discovery of Brazil. The first recital was held in the Sala Cecilia Meirelles concert hall in Rio de Janeiro, in the year 2000. Astronomy has indeed stimulated creation in erudite music. In fact, according to Dominique Proust, "the composer wants his work to be judged from its point of view as music, even if the poetical base is founded on the study of the planets." In Holst's case, the inspiration is astrological and in Almeida Prado's, the study of the universe from charts of the heavens. The rôle of astronomy in the diversity of Brazilian culture- despite being little known the world over- has been immense. Thus, in forms as different as popular and erudite music, we find compositions and librettos inspired by the stars, in eclipses, and in phenomena as rare as the passage of Venus in 1882, the appearance of Halley's Comet in 1910, or in the Big Bang theory in the 1990s. Even in the smaller scale carnival parades at the beginning of the 19th Century, astronomy was present. More recently, in the -now gigantic- 1997 parade, the samba school known as Unidos do Viradouro, under the direction of Joaozinho Trinta, proffered a new panorama of the first instants of the creation of the universe, by associating, in the white and dark of the school's participants, the idea of matter and anti-matter which reigned in the first instants of the creation of the universe, all ending in a huge explosion of happiness and dancing (samba) and music. 

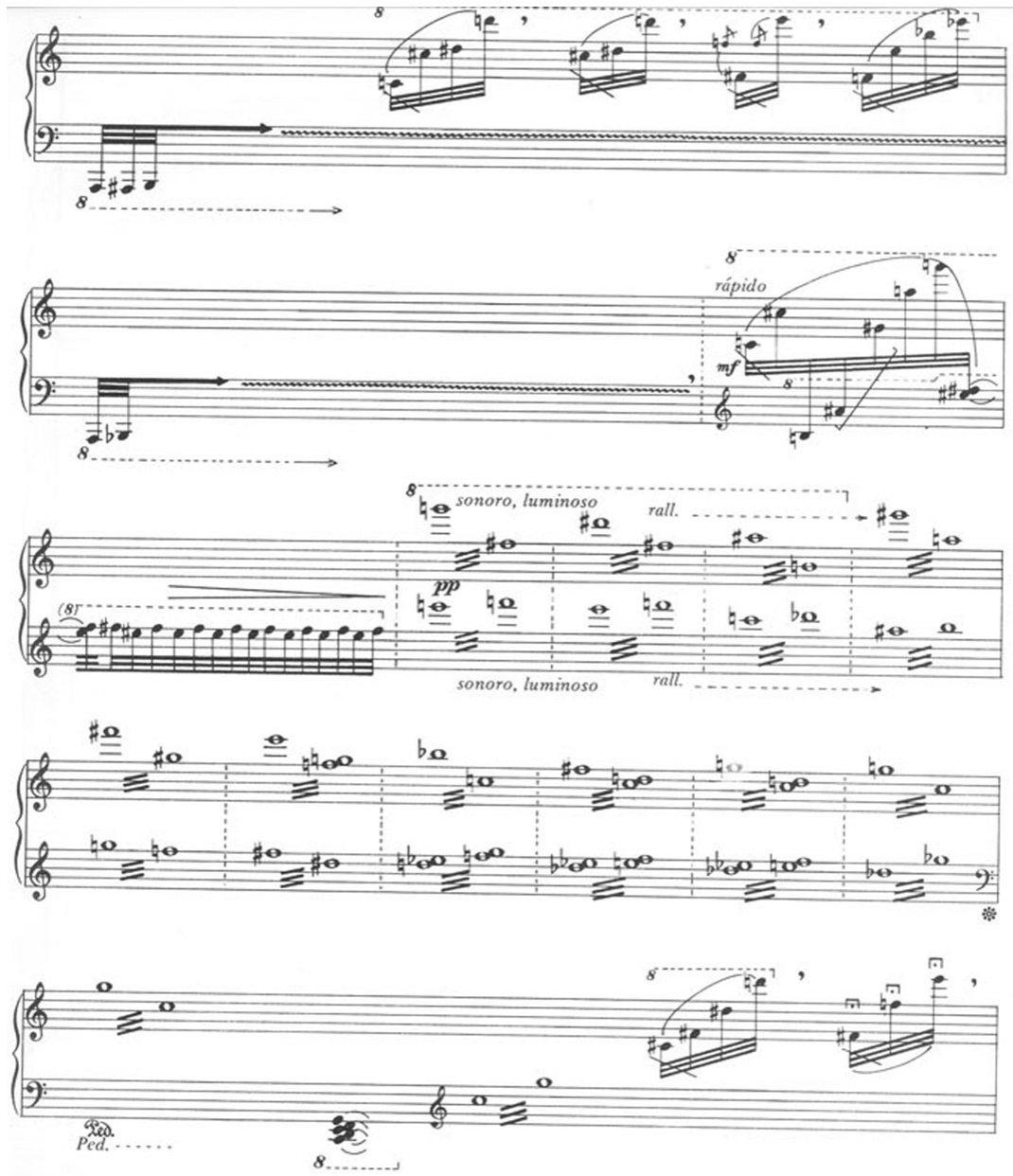

Figure 5. Extract from Abdon Milanez's A passagem de Vênus.

\section{The passage of Venus by Abdon Milanez}

Occurrences of Venus crossing with the Sun are extremely rare and occur in pairs (separated by about eight years) at intervals of a little more than a century. They are so rare, that none occurred in the 20th century and the last was sighted in 2004, with the next due in 2012. Influenced by the passage of Venus in 1882, visible in Brazil, Abdon Milanez (1858-1927) composed a polka about this astronomical event. Indeed, various musical compositions were created to commemorate the passage of Venus over the world, the best known of which is the Transit of Venus March, composed by John Philip Sousa (1854-1932) known as the March King, the leader of the United States Marine Band. The descendant of an illustrious family from the State of Paraíba in Northeast Brazil, of Portuguese-Italian origin, with much political prestige, Abdon Milanez soon moved to Rio de Janeiro, taking medicine at the Faculty of Medicine and engineering at the Polytechnic School, graduating in civil engineering in 1880. He did not study music regularly, having started late to learn the piano. In his student days, he composed polkas and waltzes, published by Casa Bevilacqua. 


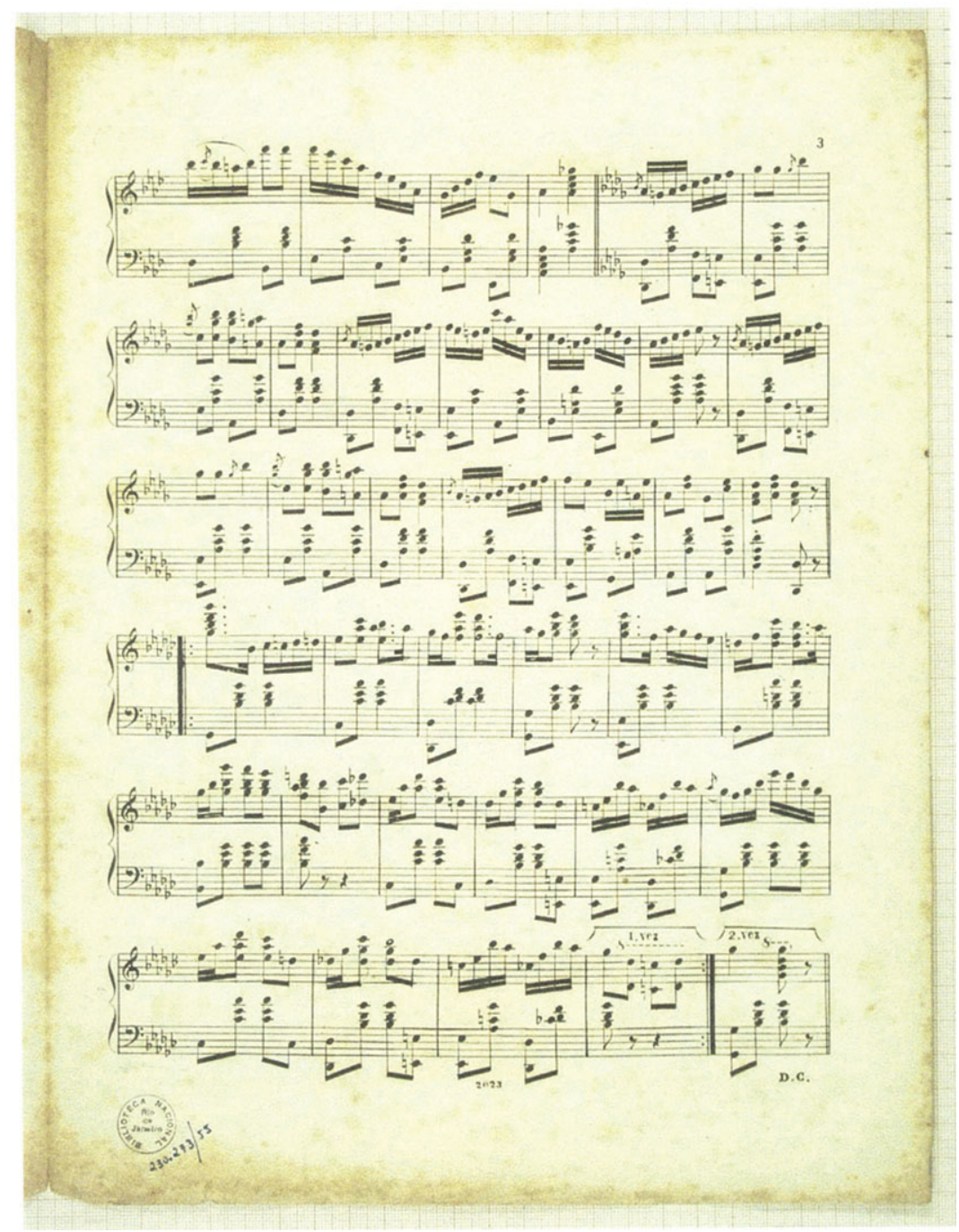

Figure 6. Extract from Abdon Milanez's A passagem de Vênus.

\section{Astronomy and poetry}

The stars proved, for innumerable poets, composers, musicians and artists to be their motivation for inspiration. However, the culture of astronomy in all the main periods of history is very much in evidence in acclaimed works. In Dante's Divine Comedy and Camões' Lusíadas, we see represented, in poetry, astronomical knowledge based on the geocentric system of Claudio Ptolemy; in Copernicus, by the Italian Giacomo Leopardi (1798-1837), there is the crowning of the Copernican revolution.

We cannot forget the influence which astronomy and its various branches, such as astrophysics, cosmology, and more recently, space research, had on Brazilian literary works. The rôle of news about astronomical discoveries and, after the coming of the space age, with the launching of artificial satellites and of space probes and telescopes, all these influences were felt in the poetry of Brazilian writers Carlos Drummond de Andrade, Murilo Mendes and Joaquim Cardozo. 
Unlike the two poets from Minas Gerais State, Carlos Drummond and Murilo Mendes, who were impressed in their youth by the vision of Halley's Comet, in 1910, the poet Fernando Py, who launched the poem Antiuniverso, with almost a thousand verses, led to astronomy by reading Jules Verne and Monteiro Lobato, was touched, not by the vision, but by the expectation, when he was twelve years old, of the return of Halley's comet in 1986. His poem, dealing with the crowning of astronomical knowledge in his time, constitutes a work comparable to the Divine Comedy, to the Lusiadas and to Leonardi's poem. If Dante and Camões favoured the geocentric Ptolemaic concept of the universe and Leopardi the heliocentric Copernican model of the universe, Fernando Py devoted his verses to relativist cosmology's latest conquests in the 20 th century, right up to recent research on cosmic walls.

The Antiuniverse is, by nature, a relativist cosmic poem, interlaced with personal reminiscences which are inserted in the poem as space-time meditations. Perhaps his interest, since his youth, in astronomy and science fiction led the poet, in his digressions, to present an up-to-date vision of the universe. Devouring parsecs, Fernando Py reached other galaxies, where he presupposes the existence of double, two-colour (blue and red) solar systems, an idea which doubtless occurred to him from reading Stanislaw Lem's Solaris.

\section{Conclusion}

In fact, astronomy has stimulated creation, since, as Dominique Proust described, the composer wishes his work to be judged by the music, even though the poetic basis rests on the study of the planets" in Holst's case, and in the case of Almeida Prado, in studying the universe from the starting point of a Chart of the Heavens. 